\title{
Perforation Peritonitis at High Altitude
}

\author{
Bhawana Amatya, ${ }^{1}$ Paleswan Joshi Lakhey, ${ }^{2}$ Prativa Pandey' \\ 'CIWEC Hospital and Travel Medicine Center, Lainchaur, Kathmandu, Nepal, ${ }^{2}$ Institute of Medicine, Tribhuvan University, \\ Kathmandu, Nepal.
}

\section{ABSTRACT}

Trekkers going to high altitude can suffer from several ailments both during and after their treks. Gastro-intestinal symptoms including nausea, vomiting, and abdominal pain are common in high altitude areas of Nepal due to acute mountain sickness or due to a gastro-intestinal illness. Occasionally, complications of common conditions manifest at high altitude and delay in diagnosis could be catastrophic for the patient presenting with these symptoms. We present two rare cases of duodenal and gastric perforations in trekkers who were evacuated from the Everest trekking region. Both of them had to undergo emergency laparotomy and repair of the perforation using modified Graham's patch in the first case and distal gastrectomy that included the perforated site, followed by two-layer end-to-side gastrojejunostomy and two-layer side-to-side jejunostomy in the second case. Perforation peritonitis at high-altitude, though rare, can be life threatening. Timely evacuation from high altitude, proper diagnosis and prompt treatment are essential for taking care of such patients.

Keywords: duodenal ulcer; Everest; hypoxia; mountaineering; trekking.

\section{INTRODUCTION}

The extreme altitude in the Himalayas of Nepal lure trekkers and tourists every year to challenge themselves to new realms. While high altitude can affect virtually all systems of the body, trekkers rescued from highaltitude can present with a myriad of symptoms apart from the usual altitude illness. In this case series, we highlight the stories of two Everest trekkers who had to curtail their treks due to acute abdomen, namely perforation peritonitis.

At a constant temperature, the volume of gas is inversely proportional to the pressure it receives according to Boyle's Law. ${ }^{1}$ Decreased barometric pressure at highaltitude $^{2}$ causes hyper-inflation of the hollow viscera, which may cause them to perforate..$^{3,4}$ Perforation peritonitis, though unusual after trekking can be a life-threatening condition, hence demands immediate attention.

This article focuses on the gravity of this illness so as to spread awareness about the spectrum of disorders that increasing altitude can generate.

\section{CASE REPORT}

A 45-year-old Korean male had been trekking in the Everest region for seven days when he developed severe nausea and vomiting at Lobuche $(4900 \mathrm{~m})$. He

Correspondence: Dr. Bhawana Amatya, CIWEC Hospital and Travel Medicine Center, Lainchaur, Kathmandu, Nepal. Email: bhawanaz@gmail.com, Phone: +977-9849944888. 
took buscopan and ascended to Gorakshep (5140 $\mathrm{m})$. While in Gorakshep, he had further episodes of vomiting, ongoing nausea and severe abdominal cramps. He was given Prednisolone 10mg, Sildenafil, Acetazolamide 250mg and Ibuprofen 400mg by a trekker doctor friend with concern of altitude illness. As his symptoms continued, he was carried down on the back of a horse from Gorakshep to Pheriche (4200 $\mathrm{m})$. After an overnight rest, a helicopter brought him to Lukla and then to Kathmandu (1330m).

At CIWEC Hospital in Kathmandu, he continued to have repeated vomiting and upper abdominal pain of severity $10 / 10$. He had pulse of $62 / \mathrm{min}$, blood pressure of $160 / 90$ $\mathrm{mmHg}$, temperature of $37.3^{\circ} \mathrm{C}$ and oxygen saturation on room air of $99 \%$. He was ill looking and appeared dehydrated. Lungs were clear and cardiac examination was normal. Abdominal examination initially revealed epigastric tenderness which was later followed by guarding and rigidity. Upright $\mathrm{X}$-ray chest showed gas under both hemi-diaphragms (Figure 1). He was referred to surgery and emergency exploratory laparotomy was done. He was found to have a solitary perforation in the anterior wall of the first part of the duodenum which was repaired using modified Graham's Patch (Figure 2). Helicobacter pylori (H. pylori) antibody in the serum was positive and he was given triple therapy for $\mathrm{H}$. pylori eradication. Post-operative recovery was uneventful and he returned to Korea.

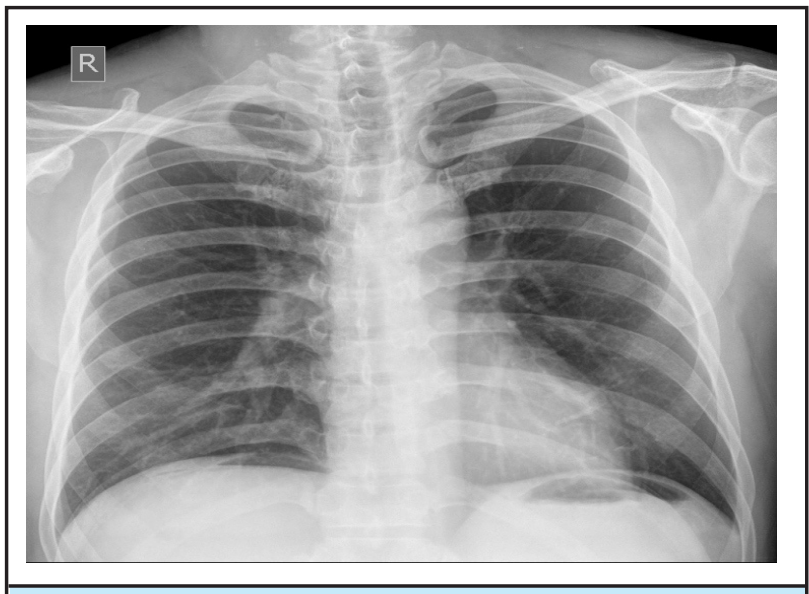

Figure 1. X-ray chest erect showing gas under both hemi-diaphragms.

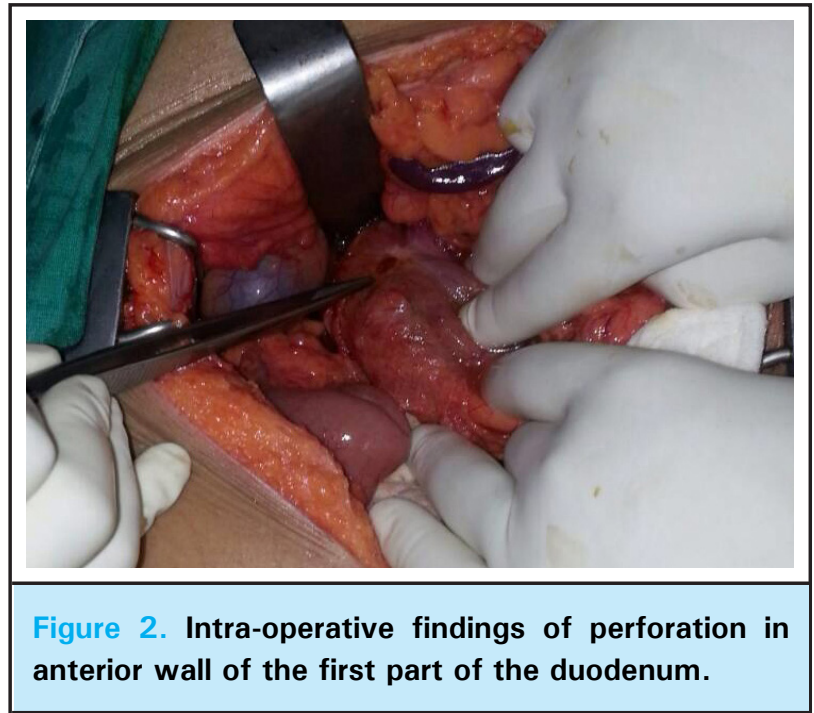

\section{CASE REPORT 2}

A 70-year-old previously healthy American male trekker was seen after helicopter evacuation from Deboche $(3800 \mathrm{~m})$ in the Everest trekking region. He had been trekking for thirteen days, climbing up the Kala Pathar $(5580 \mathrm{~m})$ and reaching the Everest Base Camp $(5364 \mathrm{~m})$. On the twelfth night of his trek, he initially developed shoulder pain then woke up early in the morning with severe abdominal pain. The abdominal pain was aggravated by sudden movement, touching or deep breathing. He had been having diarrhoea until 5 days ago but had no bowel movement for the last 3 days. He had been taking Tab. Ciprofloxacin $500 \mathrm{mg}$ twice daily for 5 days, which he had stopped 5 days ago, Cap Loperamide, Ibuprofen 600 mg twice as well as Hydrocodone $10 \mathrm{mg}$ to relieve his pain. However, the pain had not subsided and he had to be helicopter evacuated to Kathmandu.

Upon arrival at CIWEC, his vitals were blood pressure $120 / 80 \mathrm{mmHg}$, pulse $88 / \mathrm{min}$, temperature $36.7^{\circ} \mathrm{C}$, respiratory rate $22 / \mathrm{min}, \mathrm{spO}_{2} 98 \%$ in room air. $\mathrm{He}$ appeared dehydrated. His abdominal examination revealed diffuse severe tenderness with rigidity and sluggish bowel sounds. Chest, cardiovascular, and neurological examinations were normal. Chest X-ray erect with both domes of diaphragms showed gas under the right dome of diaphragm suggestive of pneumo-peritoneum (Figure 3). Emergency surgical consultation was followed by emergency laparotomy at another facility. One litre of sero-purulent fluid was present in the peritoneal cavity with large perforation in the pre-pyloric region in the anterior wall $(\sim 2 \mathrm{~cm}$ ) with surrounding induration (Figure 4). Thorough lavage of the peritoneal cavity was done with 5 litres of warm saline. He underwent distal gastrectomy that 
included the perforated site, followed by two-layer end-to-side gastrojejunostomy and two-layer side to side jejunostomy. Two drains were placed- one in Morrison's pouch and the other in the pelvis.

Post-surgery, he was kept in the intensive care unit at CIWEC, required inotropic support with Noradrenaline which was later tapered and stopped on third postoperative day. He was also kept under antibiotics Piperacillin/Tazobactam, oxygen and pain management. He developed pneumonia on the second post-operative day. He was hospitalized for ten days, then returned to his home country after his condition was stable. About three weeks post his arrival in the US, he developed an abscess on the site of the surgical incision. He was hospitalized there for a week and was treated with several different antibiotics for a month. Thereafter, he recovered and has remained in good health.

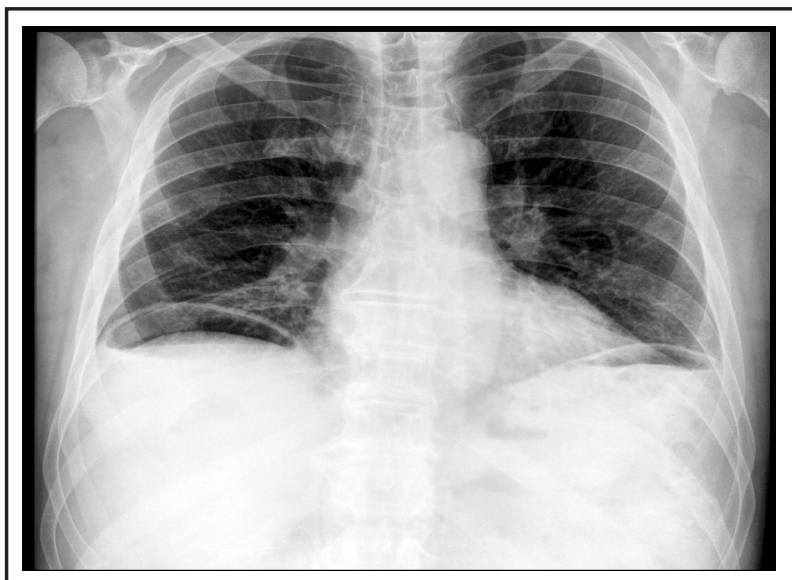

Figure 3. Plain radiograph of chest erect view showing gas under right dome of diaphragm.

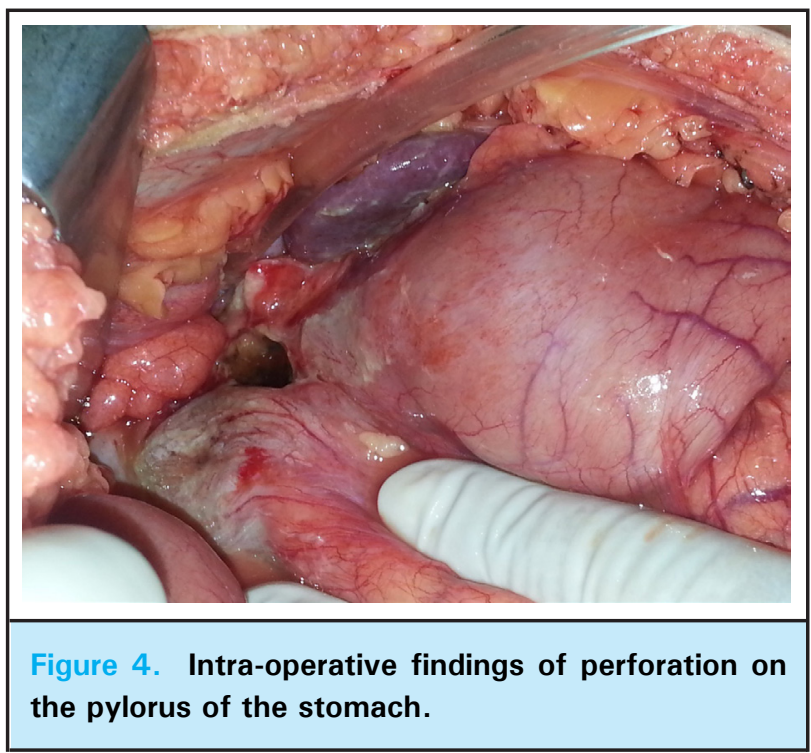

\section{DISCUSSION}

Symptoms of acute mountain sickness including headache, nausea and vomiting are common in trekkers to high altitude areas of Nepal where rates of AMS can be up to $50 \% .^{5}$ These symptoms are equally common due to a gastro-intestinal infection which is the most common ailment in travellers to Nepal. ${ }^{6,7}$ Our first patient had symptoms of nausea, vomiting initially with later development of abdominal pain. He was initially treated for AMS with steroid and lbuprofen both of which could have made the duodenal ulcer worse. Helicobacter pylori infection is known to be associated with peptic ulcer disease ${ }^{8}$ and this patient was positive for this infection. He was evacuated to Kathmandu promptly where he was noted to have a surgical abdomen. Prompt treatment of perforated duodenal ulcer led to a speedy recovery. H. Pylori infection, combined with NSAIDs and steroid use at high altitude most likely led to the DU with perforation. He did well following surgery. In our second patient, it is possible that NSAID use had a role in causing gastric perforation. Although perforation peritonitis was recognized quickly in our facility, his advanced age might have led to a complicated course post operatively. ${ }^{9}$

Medical facilities for performing surgeries do not exist in high altitude areas of Nepal and patients have to be evacuated to lower altitudes for prompt diagnosis and treatment. Helicopter rescues from the mountains are readily available in Nepal and this may be the reason patients survive life threatening conditions. ${ }^{10,11}$

Did hypoxia at high altitude have a role in causing perforation in these patients? Increased incidence of gastric ulcers and bleeding have been described in Chinese lowlanders who moved to high altitude to work on a railroad project. ${ }^{12}$ The risk increased in persons who consumed large amounts of alcohol, took aspirin or dexamethasone. ${ }^{12,13}$ Gastric mucosal lesions and gastrointestinal bleeding from peptic ulcers have also been noted in Japanese mountaineers. ${ }^{14}$ Perforation of duodenal ulcer was noted in pilgrims from India during "Shri Amarnath Ji Yatra" where devotees do a difficult trek of $40 \mathrm{~km}$ to reach a holy cave at $4200 \mathrm{~m} .{ }^{15}$ Although increased incidence of gastric mucosal lesions have been noted in trekkers and mountaineers from the eastern cultures, this has not been a prominent finding in the Western literature. If one looks at the various organ systems of the body at extreme altitudes, most of them show some impairment attributable to hypoxia for example reduced gastrointestinal absorption. ${ }^{16}$

Case reports from patients returning from air travel, which exemplify high altitude, have shown that high altitude predisposes to causing gaseous expansion and sometimes perforation in the digestive tract. ${ }^{3,17}$ 
Healthcare providers and trekkers should be aware of the wide array of illnesses that may appear in the extreme conditions of high-altitude.

Abdominal cramps and vomiting can also be symptoms of acute mountain sickness but as in these cases, with wide differentials in mind, life-threatening emergencies can be recognized and treated promptly.

\section{Conflict of Interest: None.}

Consent: JNMA Case report consent form was signed by the patient and the original is attached with the patient chart.

\section{REFERENCES}

1. West JB. Robert Boyle's landmark book of 1660 with the first experiments on rarified air. Journal of Applied Physiology. 2005;98(1):31-9. [PubMed]

2. B West J, Lahiri S, Maret K, Peters R, J Pizzo C. Barometric pressures at extreme altitudes on Mt. Everest: Physiological significance. 1983. [PubMed]

3. Kenfack R, Debaize S, Sztern B, Joukovsky P. [Perforation of a hiatal hernia after a high altitude flight]. Rev Med Liege. 2007;62(3):144-6. [PubMed | PMC]

4. Morgan J, Sadler MA, Yeghiayan P. Spontaneous pneumomediastinum in a patient with recent air travel. Emergency Radiology. 2007;14(6):457-9. [PubMed | DOI]

5. Hackett PH, Rennie D, Levine HD. The incidence, importance, and prophylaxis of acute mountain sickness. Lancet . 1976;2(7996):1149-55. [PubMed]

6. Greenwood Z, Black J, Weld L, O'Brien D, Leder K, Von Sonnenburg F, et al. Gastrointestinal infection among international travelers globally. J Travel Med . 2008;15(4):221-8. [PubMed]

7. Pandey P, Bodhidatta L, Lewis M, Murphy H, Shlim DR, Cave W, et al. Travelers' diarrhea in Nepal: an update on the pathogens and antibiotic resistance. J Travel Med. 2011;18(2):102-8. [ [PubMed | PMC]

8. Bashinskaya B, Nahed BV, Redjal N, Kahle KT, Walcott BP. Trends in Peptic Ulcer Disease and the Identification of Helicobacter Pylori as a Causative Organism: Population-based Estimates from the US Nationwide Inpatient Sample. J Glob Infect Dis. 2011;3(4):366-70. [PubMed | Full Text]
9. Christiansen P, Jensen HE, Amdrup E, Fenger C, Lindskov J, Nielsen J, et al. Gastric ulcer in old age. Acta Chir Scand. 1978;144(7-8):491-4. [PubMed | PMC]

10. Shlim DR, Houston R. Helicopter rescues and deaths among trekkers in Nepal. JAMA. 1989;261(7):1017-9. [PubMed]

11. Williams KL. Exped 2010--the challenges of an expedition doctor. J R Army Med Corps. 2011;157(1):121-3. [PubMed | PMC]

12. Wu TY, Ding SQ, Liu JL, Jia JH, Dai RC, Zhu DC, et al. High-altitude gastrointestinal bleeding: An observation in Qinghai-Tibetan railroad construction workers on Mountain Tanggula. World J Gastroenterol. 2007;13(5):774-80. [PubMed [ Full Text]

13. Subedi BH, Pokharel J, Goodman TL, Amatya S, Freer L, Banskota N, et al. Complications of steroid use on Mt. Everest. Wilderness Environ Med. 2010;21(4):345-8. [PubMed [ Full Text]

14. Sugie T, Adachi M, Jin-Nouchi $\mathrm{Y}$, Matsubayasi $\mathrm{K}$. Gastroduodenal mucosal lesion at high altitude. Japanese journal of mountain medicine. 1991;11(1):55-8. [Full Text]

15. Mir IS, Mir M, Ahmed M. Profile of non traumatic surgical disorders found in the pilgrims/trekkers travelling to Shri Amarnath Ji cave. Indian J Med Res. 2008;128(6):740-3. [PubMed]

16. West JB. Tolerance to severe hypoxia: lessons from Mt. Everest. Acta Anaesthesiol Scand Suppl. 1990;94:18-23. [PubMed]

17. Blumen IJ, Rinnert KJ. Altitude physiology and the stresses of flight. Air Medical Journal. 1995;14(2):87-100. [PubMed] 